\title{
Designing the next generation of climate adaptation research for development
}

\author{
Lindsey Jones ${ }^{1,2}$ (1) Blane Harvey ${ }^{2,3} \cdot$ Logan Cochrane $^{4,5} \cdot$ Bernard Cantin $^{6}$. \\ Declan Conway $^{1} \cdot$ Rosalind J. Cornforth $^{7} \cdot$ Ken De Souza $^{8} \cdot$ Amy Kirbyshire ${ }^{9}$
}

Received: 17 March 2017 / Accepted: 8 November 2017 / Published online: 23 November 2017

(C) The Author(s) 2017. This article is an open access publication

\begin{abstract}
Adaptation research has changed significantly in recent years as funders and researchers seek to encourage greater impact, ensure value for money and promote interdisciplinarity across the natural and social sciences. While these developments are inherently positive, they also bring fresh challenges. With this in mind, this paper presents an agenda for the next generation of climate adaptation research for development. The agenda is based on insights from a dialogue session held at the 2016 Adaptation Futures conference as well as drawing on the collective experience of the authors. We propose five key areas that need to be changed in order to meet the needs of future adaptation research, namely: increas-
\end{abstract}

Editor: Shuaib Lwasa.

Lindsey Jones

1.jones3@1se.ac.uk

Blane Harvey

b.harvey@odi.org.uk

Logan Cochrane

logan.cochrane@carleton.ca

Bernard Cantin

bernard.Cantin@agr.gc.ca

Declan Conway

d.conway@1se.ac.uk

Rosalind J. Cornforth

r.j.cornforth@ reading.ac.uk

Ken De Souza

k-desouza@dfid.gov.ac.uk

Amy Kirbyshire

a.kirbyshire@cdkn.org.uk ing transparency and consultation in research design; encouraging innovation in the design and delivery of adaptation research programmes; demonstrating impact on the ground; addressing incentive structures; and promoting more effective brokering, knowledge management and learning. As new international funding initiatives start to take shape, we underscore the importance of learning from past experiences and scaling-up of successful innovations in research funding models.

Keywords Adaptation $\cdot$ Research $\cdot$ Funding $\cdot$ Development
1 London School of Economics, Grantham Institute on Climate Change and the Environment, Houghton Street, London WC2A 2AE, UK

2 Overseas Development Institute, Risk and Resilience Programme, 203 Blackfriars Road, London SE1 8NJ, UK

3 Department of Integrated Studies in Education, McGill University, 3700 McTavish St, Montreal, QC H3A 1Y2, Canada

4 International Development Research Centre, 150 Kent St, Ottawa, ON K1P 0B2, Canada

5 Carleton University, Global and International Studies, 1125 Colonel By Drive, Ottawa, ON, Canada

6 Agriculture and Agri-food Canada, 1341 Baseline Road, Ottawa, ON K1A 0C5, Canada

7 University of Reading, Walker Institute, Reading RG6 7BE, UK

8 Department for International Development, Research and Evidence Division, 22 Whitehall, London SW1A 2EG, UK

9 Climate and Development Knowledge Network, 203 Blackfriars Road, London SE1 8NJ, UK 


\section{Introduction}

The funding landscape for adaptation research in developing countries has evolved significantly in the past decade. Research funders are placing greater emphasis on ensuring that research leads to impact on the ground. Moreover, they increasingly use models of multi-project programming ${ }^{1}$ that demand collaborative and transdisciplinary research approaches - mirroring trends in the international development research community more broadly. The reasons for this shift are diverse. They reflect not only a recognition of the multidimensional nature of 'wicked' problems like climate and development (Rittel and Webber 1973; Turnpenny et al. 2009), but shifting realities and priorities across many adaptation funding agencies: from government research councils to development donors (OECD 2014). These shifts include the emergence of the so-called 'results agenda' (Vallejo and Wehn 2016), with its strong focus on measurable progress in the form of outputs or outcomes, as well as mounting pressure on governments to deliver programming at ever-lower cost.

There is good reason to believe that many of these changes to the funding and programming modalities of adaptation research are here to stay. Funding bodies are increasingly using large multi-project programmes to scope and disburse large quantities of financing for adaptation and development research - such as the Collaborative Adaptation Research Initiative in Africa and Asia (CARIAA) and Future Climate For Africa (FCFA) programmes. In principle, the evolution towards collaborative, coordinated and transdisciplinary programming in adaptation research is positive. It takes adaptation research away from the much-critiqued siloed, 'ivory tower' models towards one that many argue is better aligned with the complex and locally grounded nature of climate adaptation and development challenges (Lang et al. 2012; Mustelin et al. 2013). However, this new research approach faces a range of novel challenges related to: the breadth of knowledge it must draw upon; the interplay between social, biophysical and political drivers of change; the challenge of competing timescales and levels of uncertainty across them; and the urgency with which widely actionable solutions are being sought from research findings (De Souza et al. 2015). As such, climate adaptation and resilience are rightly considered 'grand' research challenges by many funding bodies (Kuhlmann and Rip 2014; Reid et al. 2010). A move towards

\footnotetext{
${ }^{1}$ Multi-project programmes are large programmes, typically funded through a single mechanism and addressing a common theme, in which multiple projects are grouped together under a wider umbrella (Buffardi and Hearn 2015). Examples in the climate and development domain include the Conflict and Cooperation in the Management of Climate Change (CCMCC) programme of the Netherlands Organisation for Scientific Research and DFID and the Collaborative Adaptation Research Initiative in Africa and Asia (CARIAA) of the International Development Research Centre and DFID.
}

large-scale, collaborative and use-oriented research models, therefore, seems timely and highly appropriated.

We see the commissioning and design of adaptation research as a key, but an often under-examined dimension of generating high-quality research and promoting development impact on the ground. Moreover, greater evidence is needed on how the design of climate adaptation research programmes can help maximise their potential to not only drive forward our understanding of the complexities of adaptation within socio-ecological systems, but also to ensure that it is ultimately put to use. There is also a need to better understand the challenges faced in adapting existing institutions, incentive structures, partnerships and models of research delivery to fit this new approach (Cochrane et al. 2017). To date, however, the research community has been slow to adapt and learn from the first generation of adaptation research designed around a collaborative, multi-project programme model (Klein et al. 2017). Despite the growing programme based upon which learning and innovation can occur, we believe that evolutions in programme design have not kept pace with changes in the approaches to research.

With the above in mind, we present an agenda for the next generation of climate adaptation research for development. Our aim is to provide insight and guidance to the design and practice of adaptation research, in contrast with the frequent focus on knowledge gaps and research priorities. The agenda draws on contributions from a stakeholder dialogue at the 2016 Adaptation Futures conference in Rotterdam entitled 'Planning the next generation of adaptation research: How to coordinate, broker and amplifying large research consortia to achieve development impact'. The session involved a cross section of adaptation funders, researchers and representatives from international research coordination 'hubs' and examined the limitations and positive developments in the adaptation for development landscape. Our proposed agenda also draws on the depth and experience of the paper's authors in having engaged in adaptation research, practice and funding for many years.

\section{An agenda for the next generation of climate adaptation research for development.}

Here, we propose five key areas that require further attention to improve the design and delivery of adaptation research. These areas are increasing transparency and consultation in research design; encouraging innovation in the design and delivery of adaptation research programmes; demonstrating impact on the ground; addressing incentive structures; promoting more effective brokering, knowledge management and learning. For each, we offer recommendations to support more effective design and delivery of climate adaptation research throughout the research life cycle (see Fig. 1). 


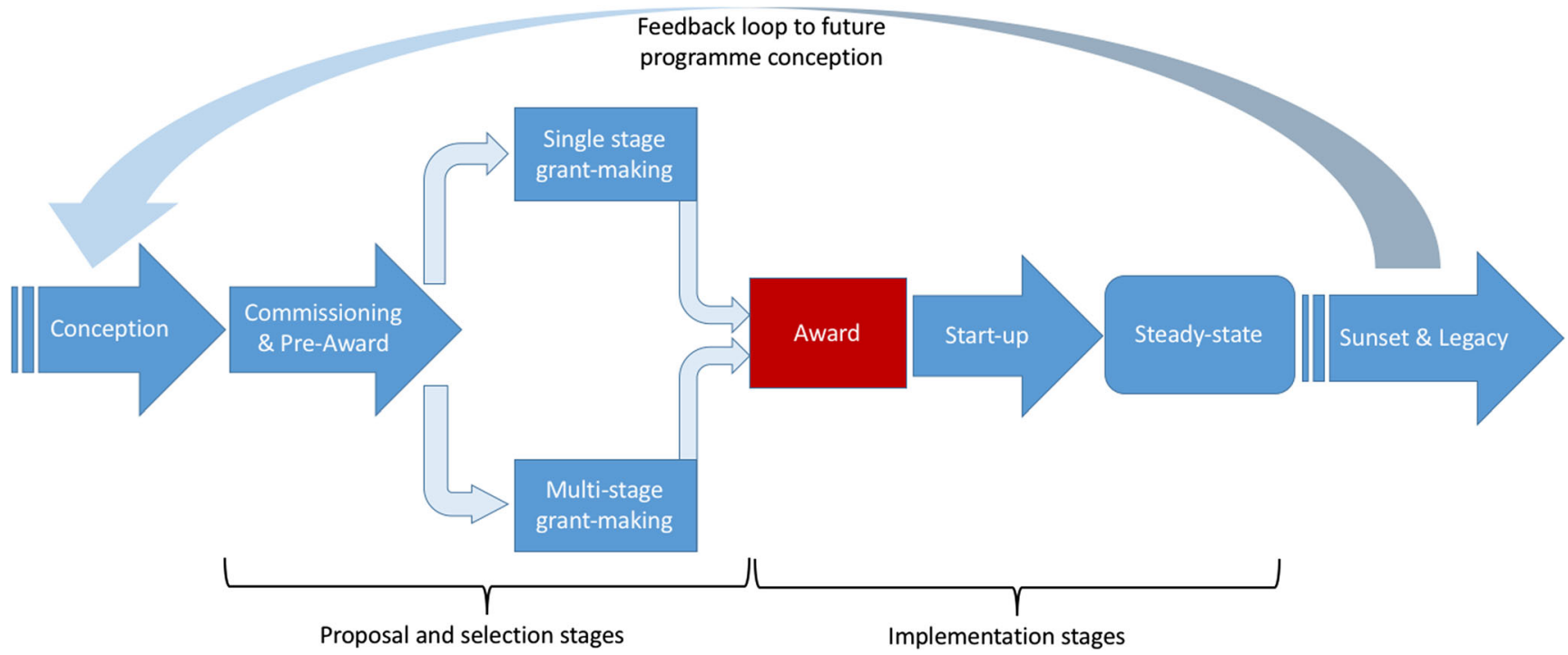

Fig. 1 The typical life cycle of an adaptation research programme

Together, these form an agenda for funders, practitioners and communities to consider in implementing future adaptation research for development.

In order to allow for a more focused assessment, we concentrate primarily on adaptation research delivered in the context of developing countries. We also base our discussion on the programming activities of bilateral and multilateral research funders located in Europe and North America-responsible for a significant proportion of financial flows in support of international adaptation research.

\section{Increasing transparency and consultation in adaptation research design}

In reflecting on the state of adaptation research, it is first useful to consider the lifecycle of a typical research programme, from scoping and grantmaking through to implementation and legacy. While most attention tends to focus on the design and delivery of a research programme, many of the factors that influence adaptation research programmes take shape long before a research call is announced - during the programme's initial conception. ${ }^{2}$

Some of the pre-commissioning drivers and choices behind the design of an adaptation research programme are openly visible. They may relate to a funder's prior commitments and track record in supporting adaptation research or their desire to contribute to a priority area of research or policy interest. Many funders will tailor research calls and programmes towards their particular thematic and geographic priorities. These are often linked to national and regional ties, common language and culture or historical associations - from colonial ties to trade and investment interests (Berthelemy 2006).

\footnotetext{
${ }^{2}$ Leemans (2016) provides useful insights on these dynamics based on the experience developing the Future Earth research platform.
}

Many funders will host pre-call consultations that allow for formal feedback on the planned content and make-up of future research programmes.

However, many other drivers that shape commissioned research are not publically visible. These are comprised of the wider political, institutional and economic factors that shape research design (Eyben 2015). For example, funders are continually being engaged by a range of actors - from think tanks and universities to NGOs, even other government agencieseach interested in shaping how and where funds are spent on adaptation. The personal thematic interests and operational preferences of key technical and programmatic staff within funding organisations may also play a strong role in shaping the design and delivery of research programmes (Green 2016). At the same time, programming is constrained by often rigid bureaucratic procedures. This applies not only to research programme development, but the politicised nature of climate-related research spending within many Northern bilateral funding agencies (Swart et al. 2009). One such example is the sensitive nature of the 'Loss and Damage' agenda where developments in attributional climate science, ongoing deliberations in the UNFCCC negotiations and issues of liability each collide, stalling progress on the issue (James et al. 2014). Accordingly, proposed research programmes often have to wait for political windows of opportunity and are then frequently rushed through as a result, or are re-cast to fit with new emerging priorities that may not be in line with the original scoping and design. As a consequence of these invisible drivers, research scoping and programme design may not actually speak to adaptation priorities, or may be designed around delivery modalities that are already known to be less than ideal.

Changing the norms and processes that play out behind closed doors is inherently difficult. However, many funders 
have taken reassuring steps towards opening up of the development of research programmes and publically engaging with stakeholders before the launch of research call. Supporting more inclusive design of large adaptation research programmes also calls for a rethink of the incentive structures used to manage and evaluate large research consortia. This necessitates the trialling of new ways of consulting and commissioning adaptation research, as we explore further below.

\section{Encourage innovation in adaptation research design}

Moving further along the programme life cycle to the processes of commissioning and awarding research, we see considerable advances in recent years in encouraging funders of adaptation research to explore new models of commissioning and awarding. Two key trends emerge from our reflections.

New design modalities First, rather than simple single-stage (proposal and selection) processes, there is now a move towards multi-stage competitions with research consortia encouraged to develop their ideas and structure over time - often through the provision of seed or proposal development funds. The types of grant-making models among adaptation funders have also proliferated, with "Action Labs", ${ }^{3}$ matchmaking workshops ${ }^{4}$ and catalyst grants ${ }^{5}$ providing but a few examples of new ways of awarding adaptation research that promote collaboration and seeding of ideas. Reasons for such innovations are manifold and recognise the challenges faced in forging new relationships and research delivery models. For example, funders are recognising the importance of trialling innovative methods of research engagement and forging new, more effective and equitable partnerships between Northern and Southern institutes (Dodson 2017). Another interesting example is the opportunities and synergies fund under the CARIAA programme. Here, funding is being allocated in the design phase of programmes to support the emergence of new ideas as the research progress. This not only permits more flexible modes of funding during implementation but also allows for research programming to be more responsive to changing circumstances and needs.

Not all adaptation research need be the product of a codesign process between funders, researchers and users. Indeed, these processes take considerable time and resources to do effectively - which can easily eat away at scarce research budgets. But these innovations are allowing funders and researchers opportunities to maximise the odds of creating meaningful partnerships. We believe this should be encouraged wherever relevant. Above all, efforts to trial new

\footnotetext{
${ }^{3} \mathrm{http} / / / \mathrm{cdkn}$. org/event/cdkn-action-lab/

4 https://www.youtube.com/watch? $\mathrm{v}=\mathrm{n} w \mathrm{XbN}$ 4Rfu7U

5 http://www.rcuk.ac.uk/pe/embedding/
}

approaches should also encourage funders and researchers to become more comfortable with the risks (and potential for failure) associated with innovation. Lesson sharing across adaptation research programmes, in cases where new partnership models prove ineffective or require considerable additional support, must therefore become a core component of research design. Further research is also needed to provide robust evidence for the benefits and limitations of different research commissioning and management options.

New approaches to prioritisation Second, funders are increasingly seeking to align the thematic foci of new adaptation research programmes with policy priorities in impacted countries. This shift has received broad support from adaptation researchers and practitioners; alike, as it recognises the importance of ensuring that research speaks directly to needs on the ground. However, the limitations of demanddriven models must also be considered. Just as with researchers, getting decision-makers to agree on key adaptation priorities is a challenge, not only due to differing values but also the politically sensitive nature of many adaptation trade-offs (Tschakert et al. 2016). Decision-makers may not fully understand the benefits and limitations of research available to them. Research consultations that prioritise the views of national policy actors may also overlook the needs and concerns of local communities - particularly in countries where vulnerable groups are politically marginalised (Eriksen et al. 2015). In addition, and building on the points related to transparency above, few funders invest the time and resources needed to systematically gather, synthesise and rank the priorities of a range of intended beneficiaries. This often results in priorities that are unrepresentative of user needs or ill-suited to being addressed by current research capacities.

An example of adaptation research funding that explicitly sought to embed stakeholder demand into research design can be found in the CARIAA programme. The selection of CARIAA research consortia was undertaken in a two-stage process. Based upon a preliminary concept note submission, 11 research consortia were short-listed and given a proposal development grant specifically designed to finance engagement with the communities and decision-makers in areas where consortia planned to undertake research. For their full proposals, the short-listed consortia were expected to demonstrate how they had taken this information into account in the research partnership configuration, planned activities and objectives.

Despite these misgivings, we believe that the move towards demand-driven research prioritisation is inherently positive. More can be done to improve the process of taking stock of users' needs, feeding them into the design of adaptation research programmes and even allowing for situations where adaptation may not fit with local priorities (Conway and 
Mustelin 2014). This includes committing adequate resources to consultative exercises; establishing more robust methods for gathering and assessing user needs that span a range of stakeholders (particularly poor and marginalised groups that may be under-represented in formal processes); motivating researchers to engage with decision-makers in the research design process in more than tokenistic ways. There is no one-size-fits-all approach to addressing the challenges, though advances in multi-stage consultative processes adopted by major adaptation donors are an important step forward.

\section{Transform adaptation research through appropriate incentives}

A key element of both commissioning and implementation processes along the adaptation research life cycle relates to incentive structures. Incentives shape how individual projects are delivered and the kinds of outputs and outcomes that they strive towards. In the UK, for example, the Research Excellence Framework (REF) heavily shapes the priorities and actions of many academic institutes and individuals. Getting these right requires a detailed understanding of the incentives of different stakeholders involved, particularly for transdisciplinary, collaborative and use-oriented research. Positioning research for use in policy contexts, for instance, calls on academics to publish shorter, more prescriptive outputs such as briefs and engage directly in national and subnational policy processes - a far cry from academia's mainstays of journal articles and academic conferences. Encouraging them to do so may also mean promoting meaningful engagement between researchers with intermediaries, practitioners and decision-makers as part of the research call process. Indeed, it is the latter element that is perhaps the hardest to secure given the different values, incentives and epistemologies of respective stakeholders. Nevertheless, engagement of policy decision-makers from the outset, including in the shaping of research questions and research delivery, can promote more effective engagement and speed of uptake of research findings into decision-making processes (Steynor et al. 2016).

Reassuringly, a number of these drivers are positively reinforcing: closer engagement with important policy agendas can give researchers new insights for their own research and raise the profile of their work. In addition, as adaptation researchers and research programmes take on certain knowledge brokering roles and become more directly linked to implementation activities, new funding opportunities emerge, which are key incentives in and of themselves. This includes funding through non-traditional research donors such as charities and philanthropic foundations like the Rockefeller Foundation. However, this shift also brings with it added challenges given the different management and reporting models, incentive structures and expected outcomes associated with these new research funders. For example, while large research programmes have found it relatively straightforward to document academic and written outputs, monitoring and evaluation of how research is being used and its effectiveness in supporting decision-making has proven a significant challenge - one that is mirrored across wider research disciplines (Stern 2016; Förch et al. 2014). We argue that more needs to be done to support innovation in mapping and tracking pathways to impact of adaptation research through approaches such as outcome mapping, realist evaluation and contribution analysis. Both research funders and adaptation researchers have much to learn from the practitioner community in this regard that has long had to document impacts of their interventions to development funders.

\section{Prioritise knowledge management, brokering and learning within and across programmes}

Many lessons have been learned since the implementation of early adaptation research programmes such as the Assessments of Impacts and Adaptation to Climate Change (AIACC) programme (Leary et al. 2007). However, ensuring that the strengths and weakness of past approaches inform the design and management of future adaptation research calls remains a challenge. Much of the learning that has carried forward from prior research programmes has remained as individual and institutional knowledge, with few formal platforms for reflecting on the merits of different adaptation funding models. Now, the pressure to demonstrate that the growing investment into adaptation research and practice yields tangible dividends makes these learning and knowledge exchange processes imperative.

It is the promotion of intra-programme learning and knowledge sharing that has seen some of the greatest progress and emphasis in recent years. Many adaptation research programmes now have embedded knowledge management units tasked with promoting collaboration and sharing emerging findings across partnerships and with the wider public. These units take many forms, ranging from support systems for knowledge management needs that are identified by individual projects themselves (such as model adopted under the Unlocking the Potential of Groundwater for the Poor [UPGRo] programme) to more independent units that are driven by overall programme objectives (as in the Future Climate for Africa [FCFA] programme). The choice of knowledge management models should be informed by the programme context and objectives and by the size, scale and capacities of individual projects within the research programme. What is clear across all of the models that we reflected upon, however, is that effective knowledge management and learning support within adaptation research programmes requires considerable resourcing. The financial and time commitments they place on researchers and 
dedicated knowledge managers alike are often greater than anticipated (Harvey et al. 2017).

In our experience, issues of knowledge management are too often treated as secondary to the research itself in programme conception and start-up phases. Dedicated units or functions may be created only after research teams/consortia within a programme have been selected — or even started their activities. Our experience suggests however that unless knowledge management is considered within the earliest stages of inception and incentives created to promote engagement with centralised knowledge management units, adaptation research programmes are unlikely to be able to deliver a collective impact that exceeds the sum of their individual research and outreach activities.

An important related development has been to support more effective brokering and intermediary roles within large adaptation research programmes. These roles can take many different shapes, but often involve tailoring and translating technical information into appropriate formats; mediating between different research disciplines; facilitating knowledge exchange between formal and informal knowledge providers; communicating user needs back to producers of adaptationrelated information (see Michaels 2009). Encouraging and empowering researchers to take on some of these brokering roles can lead to more demand-led and user-oriented research, if facilitated correctly, though it is important to recognise that not all researchers will have the capacity, time and incentive to do so. Funders and researchers alike also need to invest more heavily in supporting the capacity of specialised knowledge brokers and intermediaries - important actors in helping to facilitate the co-production of knowledge and encourage its integration into decision-making contexts (Jones et al. 2016). This is especially important in the Global South, where fewer boundary organisations exist to act as intermediaries between knowledge producers and users. It is here, where the involvement of NGOs and civil society groups within, or alongside, research consortia can add considerable value, building on their connections, outreach and engagement with decisionmakers at all scales. There is tremendous potential for dedicated intermediary and broking institutes (Boyd et al. 2013), such as the Red Cross Red Crescent Climate Centre, to support researcher's programmes in engaging with users of adaptation research and supporting its uptake into decision-making and programming. While some studies have noted that excessive emphasis on knowledge brokering could undermine the objectivity and autonomy of scientists, considerable evidence supports our assertion that brokering can ultimately strengthen scientific inquiry (Turnhout et al. 2013; Michaels 2009).

\section{Invest in adaptation research capacity in the Global South}

Perhaps, the most important aspect of an adaptation research programme is the legacy it leaves behind once the life cycle of the project has come to an end. Not only does a successful adaptation research programme with a development focus need to demonstrate considerable knowledge generation and meaningful impact, it should also serve to enhance the capacity of Southern researchers. Useful lessons can be learned from the successes of past projects like the Capacity Strengthening in Least Developed Countries for Adaptation to Climate Change (CLACC) network of fellows and large programmes like CARIAA. These have often capitalised on longer-term engagements and programming cycles as well as recognising the need and value of investing in the training of early career researchers (Moss 2016). However, barriers to Southern research capacity development require careful consideration (Hewitson 2015; Blicharska et al. 2017).

For a start, adaptation research funding calls are still heavily dominated by consortia led by Northern research institutes, even when research is intended to focus solely on developing countries. Involvement of Southern actors is too often restricted to secondary, and in some cases token participation within research consortia. Indeed, in the case of Africa, there are few large adaptation research projects that are led by African institutes located outside of South Africa. Part of this relates to issues of institutional capacity and challenges with staff retention at many of these institutes. The talent pool available within these institutes is further restricted by the low number of MSc and $\mathrm{PhD}$ graduates specialising in climate science and adaptation research - with low levels of available funding and few university courses specialising in relevant subjects (SARUAA 2014). Southern institutes that do have the capacity to carry out world-leading research are often overwhelmed with requests to partner with Northern institutes seeking local counterparts and expertise, and are frequently overstretched as a result. Other factors relate to political and institutional barriers resulting in difficulties for many African and Asian institutes to satisfy eligibility criteria set by Northern funders, as well as potential biases in selection processes or committees which privilege higher-ranked universities in the North (Blicharska et al. 2017). Greater Southern representation in many international funding decision-making and advisory bodies could allow for Southern voices and perspectives to be shared in the commissioning, awarding and management of adaptation research.

We believe that changes to the design and commissioning of adaptation research can address some of these challenges. As an example, CDKN's Innovation Fund for climate resilience stipulates that research projects must be led by institutions from developing countries. Most other major adaptation funders now require research consortia to include Southern partners within the core make-up of a project and in some cases, target only Southern institutions. Strengthening NorthSouth partnerships is certainly not easy. Experiences from programmes such as CDKN and CARIAA report many teething problems as Southern institutes are faced with institutional and financial constraints. However, more can and should be 
done to support Southern research institutes in developing their capacity to lead and manage adaptation research projects. This not only includes technical support and engagement with Northern actors, but supporting sharing and capacity development between stakeholders in the South, and better articulating the important gains to be made from increased investment into in-country capacities on adaptation research. It also requires more equitable collaborations within projects, something that can be attributed - in part- to programme design.

In practice, 2- and 3-year project cycles are unlikely to deliver the gains needed to support research capacity. However, multi-stage grants and match-making exercises can allow researchers to explore engagement with partners, creating opportunities for alternative ways to bridge bottomup and top-down strategy and informal-versus-formal institutions. More importantly, they also allow valuable time for new partnerships to be tested and, if necessary, changed.

\section{Looking to the next generation of adaptation research programmes}

Much has been written about the need to scale up investment into research and action on climate change adaptation in vulnerable countries, particularly those in the global South. However, without effective approaches to programme scoping, design and delivery, the impact of future investments remains open to question. The development and refinement of these approaches, we argue, should not be the sole concern of technocrats in funding agencies. They should be the subject of reflection and debate among all concerned parties, including the intended users of research evidence. The dialogue and eventual set of recommendations featured in this contribution represent a first attempt to initiate this dialogue - one that we invite others in the research community to take part.

Acknowledgements The authors would like to thank participants at the session 'Planning the next generation of adaptation research: how to coordinate, broker and amplifying large research consortia to achieve development impact' at Adaptation Futures 2016 in Rotterdam, Holland. Particular thanks go to Lisa Dilling, Jean Pierre Roux, Han van Dijk and Frances Walker for comments and inputs.

\section{Compliance with ethical standards}

Disclaimer The views expressed in this paper are the authors' own and do not necessarily represent those of the organisations involved.

Open Access This article is distributed under the terms of the Creative Commons Attribution 4.0 International License (http:// creativecommons.org/licenses/by/4.0/), which permits unrestricted use, distribution, and reproduction in any medium, provided you give appropriate credit to the original author(s) and the source, provide a link to the Creative Commons license, and indicate if changes were made.

\section{References}

Berthelemy J-C (2006) Bilateral donors' interest vs. recipients' development motives in aid allocation: do all donors behave the same? Rev Dev Econ 10(2):179-194. https://doi.org/10.1111/j.1467-9361. 2006.00311.x

Blicharska M, Smithers RJ, Kuchler M, Agrawal GK, Gutiérrez JM, Hassanali A, Huq S, Koller SH, Marjit S, Mshinda HM, Masjuki HH (2017) Steps to overcome the North-South divide in research relevant to climate change policy and practice. Nat Clim Chang 7(1): 21-27. https://doi.org/10.1038/nclimate3163

Boyd E, Cornforth RJ, Lamb PJ, Tarhule A, Lélé MI, Brouder A (2013) Building resilience to face recurring environmental crisis in African Sahel. Nat Clim Chang 3(7):631-637. https://doi.org/10.1038/ nclimate 1856

Buffardi A, Hearn S (2015) Multi-project programmes: functions, forms and implications for evaluation and learning. In: A methods lab publication. Overseas Development Institute, London

Cochrane L, Cundill G, Ludi E, New M, Nicholls RJ, Wester P, Cantin B, Murali KS, Leone M, Kituyi E, Landry M-E (2017) A reflection on collaborative adaptation research in Africa and Asia. Reg Environ Chang 17:1553-1561. https://doi.org/10.1007/s10113-017-1140-6

Conway D, Mustelin J (2014) Strategies for improving adaptation practice in developing countries. Nat Clim Chang 4(5):339-342. https:// doi.org/10.1038/nclimate2199

De Souza K, Kituyi E, Harvey B, Leone M, Murali KS, Ford JD (2015) Vulnerability to climate change in three hot spots in Africa and Asia: key issues for policy-relevant adaptation and resilience-building research. Reg Environ Chang 15(5):747-753. https://doi.org/10.1007/ s10113-015-0755-8

Dodson J (2017) Building partnerships of equals: the role of funders in equitable and effective international development collaborations. UK Collaborative on Development Science, London

Eriksen SH, Nightingale AJ, Eakin H (2015) Reframing adaptation: the political nature of climate change adaptation. Glob Environ Chang 35:523-533. https://doi.org/10.1016/j.gloenvcha.2015.09.014

Eyben R (2015) Uncovering the politics of evidence and results. In The politics of evidence and results in international development: playing the game to change the rules?. Practical Action Publishing Ltd, p 19-38

Förch W, Kristjanson P, Cramer L, Barahona C, Thornton PK (2014) Back to baselines: measuring change and sharing data. Agric Food Sec 3(1):1. https://doi.org/10.1186/2048-7010-3-13

Green D (2016) How change happens. Oxford, OUP Catalogue. https:// doi.org/10.1093/acprof:oso/9780198785392.001.0001

Harvey B, Pasanen T, Pollard A, Raybould J (2017) Fostering learning in large programmes and portfolios: emerging lessons from climate change and sustainable development. Sustainability 9:315. https:// doi.org/10.3390/su9020315

Hewitson B (2015) To build capacity, build confidence. Nat Geosci 8(7): 497-499. https://doi.org/10.1038/ngeo2465

James R, Otto F, Parker H, Boyd E, Cornforth R, Mitchell D, Allen M (2014) Characterising loss and damage from climate change. Nat Clim Chang 4(11):938-939. ISSN 1758-678X. https://doi.org/10. 1038/nclimate2411

Jones L, Harvey B, Godfrey-Wood R (2016) The changing role of NGOs in supporting climate services. BRACED Resilience Intel Paper 4. Overseas Development Institute, London

Klein R, Adams K, Dzebo A, Davis M, Kehler Siebert C (2017) Advancing climate adaptation practices and solutions: emerging research priorities. Stockholm Environment Institute (SEI), Stockholm

Kuhlmann S, Rip A (2014) The challenge of addressing Grand Challenges. https://ec.europa.eu/research/innovation-union/pdf/ 
expert-groups/The_challenge_of_addressing_Grand_Challenges. pdf

Lang DJ, Wiek A, Bergmann M, Stauffacher M, Martens P, Moll P, Swilling M, Thomas CJ (2012) Transdisciplinary research is sustainability science: practice, principles, and challenges. Sustain Sci 7: 25-43. https://doi.org/10.1007/s11625-011-0149-x

Leary N, Adejuwon J, Barros V, Batimaa P, Biagini B, Burton I et al (2007) A stitch in time: lessons for climate change adaptation from the AIACC project. International START Secretariat, Washington, $\mathrm{DC}$

Leemans R (2016) The lessons learned from shifting from global-change research programmes to transdisciplinary sustainability science. Curr Opin Environ Sustain 19:103-110. https://doi.org/10.1016/j. cosust.2016.01.001

Michaels S (2009) Matching knowledge brokering strategies to environmental policy problems and settings. Environ Sci Policy 12(7):994 1011. https://doi.org/10.1016/j.envsci.2009.05.002

Moss C (2016) The Nairobi process. The next generation: ideas and experience in African researcher support. Association of Commonwealth Universities/British Academy, London

Mustelin J, Kuruppu N, Kramer AM, Daron J, de Bruin K, Noriega AG (2013) Climate adaptation research for the next generation. Clim Dev 5(3):189-193. https://doi.org/10.1080/17565529.2013.812953

OECD (2014) Research co-operation between developed and developing countries in the area of climate change adaptation and biodiversity. Organsation for Economic Co-operation and Development, Paris

Reid WV, Chen D, Goldfarb L, Hackmann H, Lee YT, Mokhele K, Ostrom E, Raivio K, Rockstrom J, Schellnhuber HJ, Whyte A (2010) Earth system science for global sustainability: grand challenges. Science 330(6006):916-917. https://doi.org/10.1126/ science. 1196263

Rittel HWJ, Webber MM (1973) Dilemmas in a general theory of planning. Policy Sci 4:155-169. https://doi.org/10.1007/bf01405730
SARUA (2014) Strengthening university contributions to climate compatible development in Southern Africa: knowledge co-production framework. Southern Africa Regional Universities Association (SARUA). Wits: South Africa

Stern N (2016) Building on success and learning from experience: an independent review of the Research Excellence Framework. Department for Business, Energy \& Industrial Strategy. Government of the United Kingdom, London

Steynor A, Padgham J, Jack C, Hewitson B, Lennard C (2016) Coexploratory climate risk workshops: experiences from urban Africa. Clim Risk Manag 13:95-102. https://doi.org/10.1016/j. crm.2016.03.001

Swart R, Bernstein L, Ha-Duong M, Petersen A (2009) Agreeing to disagree: uncertainty management in assessing climate change, impacts and responses by the IPCC. Clim Chang 92(1):1-29. https:// doi.org/10.1007/s10584-008-9444-7

Tschakert P, Das PJ, Pradhan NS, Machado M, Lamadrid A, Buragohain M, Hazarika MA (2016) Micropolitics in collective learning spaces for adaptive decision making. Glob Environ Chang 40:182-194. https://doi.org/10.1016/j.gloenvcha.2016.07.004

Turnhout E, Stuiver M, Klostermann J, Harms B, Leeuwis C (2013) New roles of science in society: different repertoires of knowledge brokering. Sci Public Policy 40(3):354-365. https://doi.org/10. 1093/scipol/scs114

Turnpenny J, Lorenzoni I, Jones M (2009) Noisy and definitely not normal: responding to wicked issues in the environment, energy and health. Environ Sci Policy 12(3):347-358. https://doi.org/10.1016/j. envsci.2009.01.004

Vallejo B, Wehn U (2016) Capacity development evaluation: the challenge of the results agenda and measuring return on investment in the global south. World Dev 79:1-13. https://doi.org/10.1016/j. worlddev.2015.10.044 